
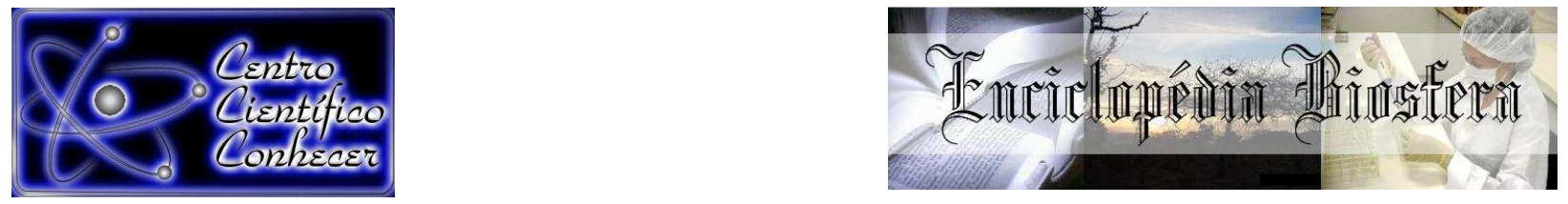

\title{
EMERGÊNCIA E QUALIDADE DE MUDAS DE Dalbergia miscolobium BENTH. (FABACEAE) EM DIFERENTES SUBSTRATOS
}

\author{
Cristiane Coelho de Moura ${ }^{1}$, Thaís Ribeiro Costa ${ }^{1}$, Paula Alves de Oliveira $^{2}$ e \\ Evandro Luiz Mendonça Machado ${ }^{3}$ \\ ${ }^{1}$ Discente do Mestrado em Ciência Florestal da Universidade Federal dos Vales do \\ Jequitinhonha e Mucuri (kinha dtna@yahoo.com.br) - Diamantina - Brasil \\ ${ }^{1}$ Discente do Mestrado em Ciência Florestal da Universidade Federal dos Vales \\ do Jequitinhonha e Mucuri \\ ${ }^{2}$ Discente do Doutorado em Ciência Florestal da Universidade Federal dos \\ Vales do Jequitinhonha e Mucuri \\ ${ }^{3}$ Professor Dr. do Departamento de Engenharia Florestal da Universidade \\ Federal dos Vales do Jequitinhonha e Mucuri
}

Recebido em: 08/04/2016 - Aprovado em: 30/05/2016 - Publicado em: 20/06/2016 DOI: 10.18677/Enciclopedia_Biosfera_2016_050

\begin{abstract}
RESUMO
Objetivando avaliar a influência de diversos substratos na produção de mudas de Dalbergia miscolobium Benth., conduziu-se um experimento em casa de vegetação do CIPEF, Diamantina, MG. Os tratamentos constituíram-se de um arranjo simples, representado pela combinação de quatro combinações de substratos: T1) Bioplant ${ }^{\circledR}$; T2) $70 \%$ Terra de subsolo $+30 \%$ Bioplant $^{\circledR}$; T3) $70 \%$ Vermiculita $^{\circledR}+30 \%$ Bioplant $^{\circledR}$; T4) $70 \%$ Vermiculita $^{\odot}+30 \%$ Casca de Arroz. O delineamento experimental adotado foi o em blocos inteiramente casualizados, com quatro repetições. A contagem da germinação foi realizada durante 30 dias. O desenvolvimento das plântulas germinadas foi avaliado por meio da sobrevivência e do crescimento em altura aos 30, 45, 60, 75 e 90 dias após a germinação. Os menores índices de sobrevivência foram observados nos tratamentos T1 e T2. O T4 é o substrato mais indicado para germinação e desenvolvimento da $D$. miscolobium pois se destacou no desenvolvimento em altura, apresentando elevado crescimento linear, bem como grande sobrevivência.
\end{abstract}

PALAVRAS- CHAVE: desenvolvimento inicial, germinação, Phoma sp.

\section{EMERGENCY AND QUALITY OF Dalbergia miscolobium BENTH. (FABACEAE) SEEDLINGS IN DIFFERENT SUBSTRATES.}

ABSTRACT

In order to evaluate the influence of different substrates in the production of seedlings of Dalbergia miscolobium Benth, it was conducted an experiment in the CIPEF greenhouse, at Diamantina, MG. The treatments consisted of a simple arrangement, represented by the combination of four substrates combinations: T1) Bioplant ${ }^{\circledR}$; T2) $70 \%$ subsoil $+30 \%$ Bioplant $^{\circledR}$; T3) $70 \%$ Vermiculite $^{\odot}+30 \%$ Bioplant $^{\circledR}$; T4) $70 \%$ Vermiculite $^{\odot}+30 \%$ rice husks. The experimental design used was in complete 
randomized block design, with four replications and ten samples per repetition. The count of germination was carried out for 30 days. The development of the germinated seedlings was assessed by survival and height growth at $30,45,60,75$ and 90 days after germination. The lowest survival rates were observed in T1 and T2. T4 is the most suitable substrate for germination and development of $D$. miscolobium, since it highlights in developing height, showing a high linear growth, as well high survival.

KEYWORDS: early development, germination, Phoma sp.

\section{INTRODUÇÃO}

O Cerrado é o segundo maior bioma brasileiro em extensão territorial, correspondente a 23,92\% do território brasileiro (IBGE, 2004; BRASIL, 2016). Segundo IBGE (2012), o Cerrado apresenta ampla distribuição nas diversas regiões do Brasil, com clima predominantemente tropical, estações secas e chuvosas bem definidas, o que proporciona a ocorrência de espécies tropófitas e caducifólias com raízes profundas. Devido a imensa diversidade apresentada por seu mosaico de diferentes fitofisionomias, elevado grau de endemismo, e de um enorme número de nascentes que alimentam rios de diversas regiões do Brasil, é crescente a preocupação com a preservação e conservação deste bioma que vem sofrendo intensa degradação devido a expansão das fronteiras agrícolas, mineração e garimpo (FERNANDES \& PESSÔA, 2011; IBGE, 2012; TOKARNIA, 2015).

A espécie nativa do Cerrado, Dalbergia miscolobium Benth., popularmente conhecida como Jacarandá-do-Cerrado (MEIRA JÚNIOR, 2013), na região do Vale do Jequitinhonha, Minas Gerais, Brasil, pertencente à família Fabaceae segundo a classificação Angiosperm Phylogeny Group III (APG III, 2009). Possui grande representatividade nas diversas fitofisionomias como o cerradão, campo rupestre e campo sujo. Possui altura entre 8 e $16 \mathrm{~m}$, com tronco de $30-50 \mathrm{~cm}$ de diâmetro, e elevado potencial econômico para a produção de madeira e para recuperação de áreas degradadas, assim como para o uso ornamental (LORENZI,1992; RIBEIRO, et al., 1994; LORENZI, 2000; SILVA JÚNIOR, 2012).

O período de floração da espécie ocorre entre os meses de Novembro a Maio e a frutificação de Maio a Junho. Cada quilo do fruto contém aproximadamente 10700 sementes, e estas permanecem viáveis por até quatro meses (ALMEIDA, et al., 1998; SILVA JÚNIOR, 2012).

Para garantir a propagação de uma espécie e, como consequência, a sua exploração de forma sustentável é de fundamental importância o conhecimento sobre a produção de sementes e o seu o processo germinativo, assim como os substratos ideais para 0 estabelecimento e desenvolvimento das plântulas (SCALON, et al., 2005; SILVA, et al, 2011; GOMES \& PAIVA, 2011).

O substrato deve ser avaliado, haja vista o importante papel que desempenha na sustentação e nutrição da muda. O comportamento de uma mesma espécie pode variar em função do substrato, portanto, deve-se avaliar o mais adequado para a produção de mudas conforme as condições apresentadas pela semente e pelas estruturas disponíveis no viveiro (TOLEDO, 1992; PAIVA \& GOMES, 1993).

Todas as fases de produção em um viveiro devem ser controladas visando determinar os fatores que alteram as características de sobrevivência e estabelecimento das mudas em campo. Desse modo, os métodos empregados durante o processo de produção devem priorizar a obtenção de mudas de qualidade, garantindo melhores resultados nos programas de implantação e recomposição das florestas nativas (FONSECA, et al., 2002; REIS, et al., 2012). Dessa forma, 
objetivou-se estimar os efeitos de substratos na emergência e qualidade de mudas de Dalbergia miscolobium.

\section{MATERIAL E MÉTODOS}

O experimento foi conduzido no período de setembro de 2014 a janeiro de 2015, em condições de casa de vegetação (1812' S; 4334' W e altitude de $1.370 \mathrm{~m})$. O ambiente possui irrigação em sistema de aspersão controlada e temperatura semicontrolada.

Foram utilizadas sementes de Dalbergia miscolobium Benth advindas de sete plantas matrizes pré-selecionadas de uma área de Cerrado stricto sensu conservada em Diamantina, Minas Gerais, localizadas entre os limites de $18^{\circ} 11^{\prime} 50,4^{\prime \prime}$ S e $18^{\circ} 12^{\prime} 10,8^{\prime \prime} S$ de latitude e $43^{\circ} 33^{\prime} 53,8^{\prime \prime} \mathrm{W}$ e $43^{\circ} 34^{\prime} 4,9^{\prime \prime} \mathrm{W}$ de longitude.

As sementes foram beneficiadas manualmente, realizando-se uma seleção visual para exclusão de sementes chochas, danificadas e deterioradas. A porção selecionada foi homogeneizada e, posteriormente armazenadas em câmara fria, no Laboratório de Sementes a $16-18{ }^{\circ} \mathrm{C}$ e $50-55 \%$ de umida de relativa do ar, permanecendo nestas condições até a instalação do experimento.

Os tratamentos constituíram-se de um arranjo simples, representado pela combinação de quatro combinações de substratos (Tabela 1). O delineamento experimental adotado foi 0 de blocos inteiramente casualizados, com quatro repetições, sendo dez amostras (2 sementes por amostra) por repetição.

TABELA 1 - Formulação dos substratos utilizados para a produção de mudas de Dalbergia miscolobium Benth. (FABACEAE) em casa de vegetação.

\begin{tabular}{ccccc}
\hline \multirow{2}{*}{ Tratamentos } & \multicolumn{4}{c}{ Constituintes (\% V/V) } \\
\cline { 2 - 5 } & Bioplant $^{\Theta}$ & Terra de subsolo & Vermiculita & Casca de Arroz \\
\hline $\mathbf{1}$ & 100 & 0 & 0 & 0 \\
$\mathbf{2}$ & 30 & 70 & 0 & 0 \\
$\mathbf{3}$ & 30 & 0 & 70 & 0 \\
$\mathbf{4}$ & 0 & 0 & 70 & 30
\end{tabular}

Todos os tratamentos receberam adubos de liberação controlada $\left(\right.$ Osmocote ${ }^{\circledR}$ ) na proporção de 15:9:12 (NPK) na concentração de $5 \mathrm{~g} / \mathrm{L}$ de substrato, com liberação entre 5 e 6 meses. Este tempo foi baseado no período de tempo necessário para emergência e formação das mudas. Utilizou-se como recipiente para alocação do substrato e disposição das sementes, tubetes plásticos $\left(180 \mathrm{~cm}^{3}\right)$.

Para a realização do teste de emergência, as sementes foram desinfestadas com Hipoclorito de Sódio durante 10 minutos, e enxaguadas posteriormente com água destilada. A contagem da foi realizada semanalmente após a instalação do experimento, até a estabilização da resposta (30 dias). Para averiguar o número de plântulas emergidas, aqui consideradas aquelas plântulas que sobressaíssem do substrato.

Para avaliação do crescimento das plântulas e qualidade das mudas foram utilizados os seguintes parâmetros: a) sobrevivência aos 30, 45, 60, 75 e 90 dias após emergência, b) altura aos 30, 45, 60, 75 e 90 dias após emergência. Para mensuração da altura utilizou-se uma régua graduada em centímetros, tomando como referência a distância do colo ao ápice da muda (gema apical). 
Os resultados da emergência foram analisados a partir de cálculos de porcentagem final (E\%) e Índice de Velocidade de Emergência (IVE), conforme GOMES \& FERNANDES (2002). Os resultados do desenvolvimento foram submetidos às análises descritivas e à análise da variância. As médias dos fatores qualitativos foram comparadas pelo teste de Tukey, e os quantitativos pela análise de regressão $(p<0,05)$.

\section{RESULTADOS E DISCUSSÕES}

Após 30 dias de observações, verificou-se que as sementes de $D$. miscolobium não apresentaram diferenças na emergência entre os tratamentos. Todas as plântulas sobressaíram-se do substrato a partir do $8^{\circ}$ dia de análise (após a semeadura), e estabilização de $100 \%$ de sementes germinadas até o $15^{\circ}$ dia após semeadura avaliado (Figura 1).

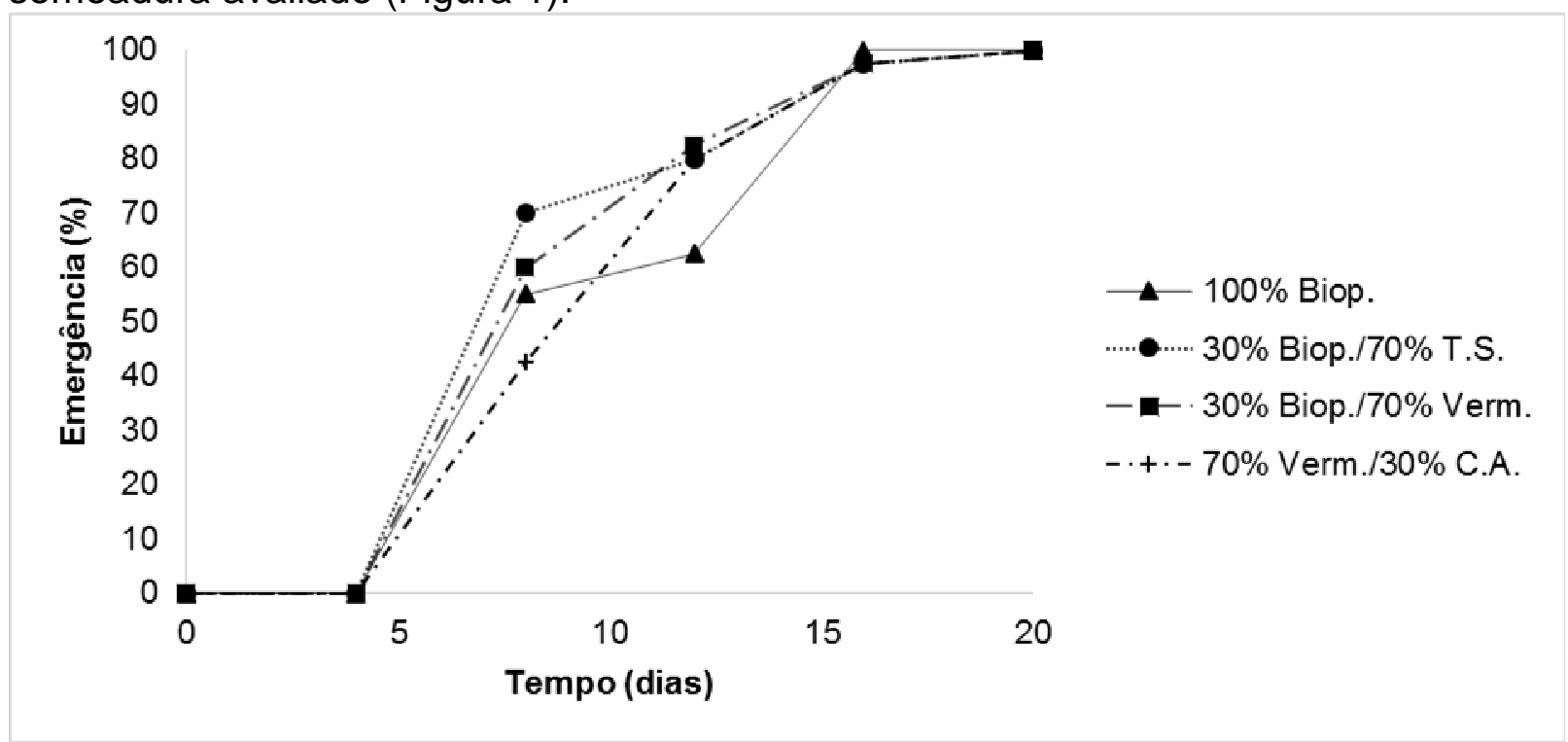

FIGURA 1 - Porcentagem de emergência de plântulas de Dalbergia miscolobium Benth. em diferentes substratos avaliados em casa de vegetação. Em que: Biop: Bioplant ${ }^{\circledR}$, T.S.: Terra de Subsolo, Verm: Vermiculita ${ }^{\odot}$ e C.A.: Casca de Arroz.

De modo geral, a espécie apresenta alta capacidade de germinação e emergência em diferentes substratos, o que vem comprovando a sua descrição apresentada por SILVA JÚNIOR (2012), que relata uma taxa de até $98 \%$ de germinação entre 7-14 dias. SASSAKI (1991) encontrou uma taxa de germinação de $98 \%$ para sementes recém-coletadas de D. miscolobium, com o início das protrusões a partir do $8^{\circ}$ dia. SILVA et al., (1998), também estudando a germinação da $D$. miscolobium, concluiu sua germinação $(100 \%)$ aos $12^{\circ}$ dias. Altas taxas de germinação do gênero Dalbergia $s p$. foram encontradas com metodologias semelhantes a esta, corroborando para o resultado deste estudo (ANDRADE et al., 2006; NOGUEIRA et al., 2014; BOUCHARDET et al., 2015).

O índice de emergência de parte aérea foi alto em todos os tratamentos, sendo o S2 com IVE de 27,41, seguida do $S 3(26,41)$, $S 4(23,97)$ e $S 1(23,95)$, ENCICLOPÉDIA BIOSFERA, Centro Científico Conhecer - Goiânia, v. 13 n.23; p. 5632016 
sendo este resultado muito relevante. Pois quanto maior a velocidade de emergência das plântulas, menor o tempo de exposição das sementes a fatores adversos, o que pode causar danos e até mesmo perda de produtividade (NAKAGAWA, 1999).

GONÇALVES et al. (2013) relatam altos valores de IVE e um melhor desenvolvimento de mudas de Enterolobium contortisiliquum (Vell) Morong (Fabaceae) utilizando substrato contendo grandes porcentagens de Vermiculita ${ }^{\circledR} \mathrm{em}$ sua composição. NOVEMBRO et al. (2007) obtiveram, para sementes de Mimosa caesalpiniaefolia, IVE máximo de 7,02 e mínimo de 0,20, com uma taxa de emergência em média de $97 \%$ para tratamentos submetidos a diferentes temperaturas o que vem confirmando a efetiva influência da Vermiculita ${ }^{\circledR}$ na composição de substratos para a germinação e posterior emergência, e um alto índice de emergência radicular para a $D$. miscolobium, ao se comparar com espécies de outros gêneros da família Fabaceae.

A sobrevivência da $D$. miscolobium variou com os diferentes tratamentos ao longo do tempo, apresentando no geral, menores índices de sobrevivência no tratamento S2 (70\% terra de subsolo $+30 \%$ Bioplant $^{\circledR}$ ) (Figura 2$)$.

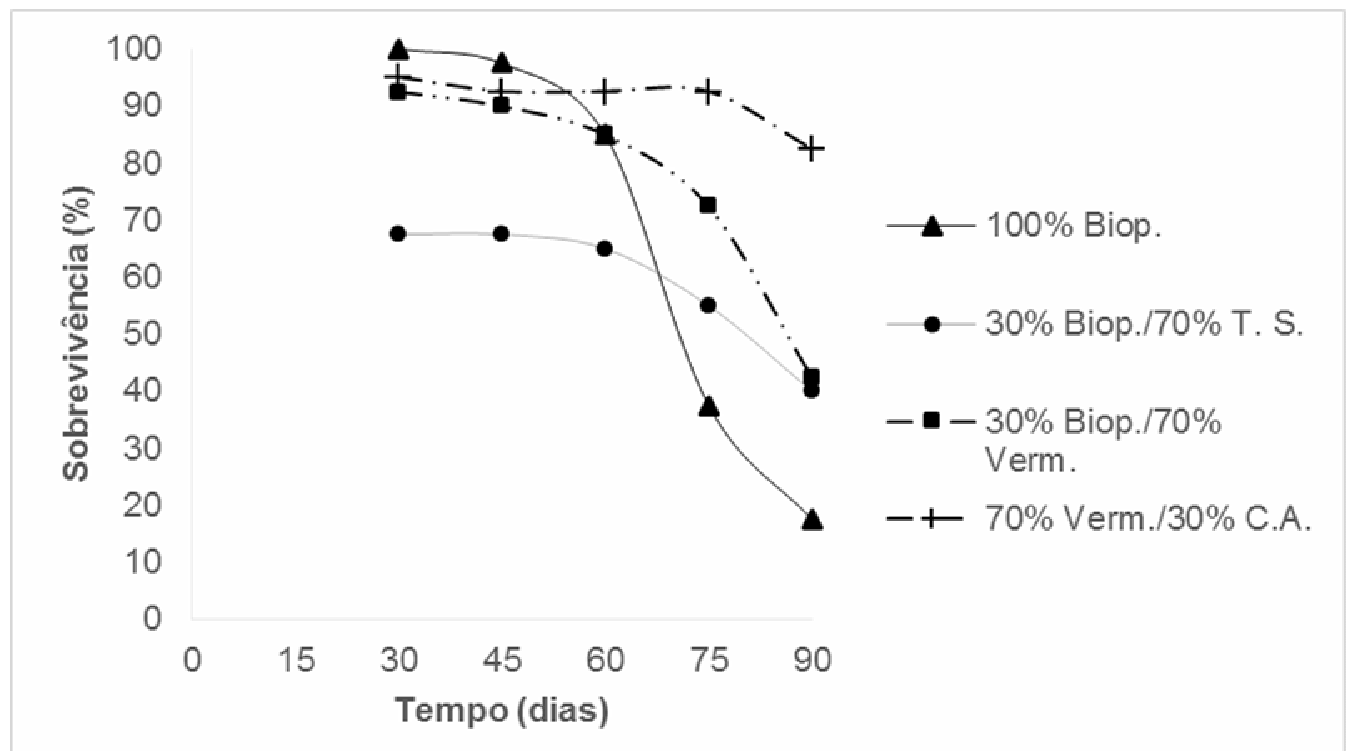

FIGURA 2 - Porcentagem de sobrevivência de Dalbergia miscolobium Benth. em diferentes substratos, em seu desenvolvimento inicial, avaliados em casa de vegetação, no CIPEF, Diamantina, MG. Em que: Biop: Bioplant ${ }^{\circledR}$, T.S.: Terra de Subsolo, Verm: Vermiculita ${ }^{\circledR}$ e C.A.: Casca de Arroz.

SILVA \& MORAIS (2013), avaliando a influência de diferentes substratos no crescimento inicial da Ormosia storage (Fabaceae), obtiveram uma taxa de mortalidade no tratamento controle, contendo apenas terra de subsolo, de $66 \%$ nos primeiros 15 dias, chegando a $88 \%$ aos 60 dias, mostrando que este substrato não é muito adequado para o desenvolvimento de plântulas da família Fabaceae. $O$ mesmo foi observado por CUNHA et al. (2005), concluindo que o substrato contendo somente terra de subsolo não atendeu às exigências nutricionais de Tabebuia impetiginosa (Bignoniaceae) em condições de viveiro, reafirmando a não eficiência deste substrato no desenvolvimento de plântulas. Este substrato possui pouca 
porosidade, baixa aeração e baixa eficiência nutricional.

COSTA et al., (2011) observaram que substrato com $100 \%$ de composto orgânico não é adequado para a formação de mudas de jatobá-do-cerrado (Hymenaea stigonocarpa Mart.), da família Fabaceae. Este resultado pode explicar a elevada mortalidade $(82,5 \%)$ da $D$. miscolobium aos 90 dias, desenvolvidas em substrato contento em sua composição $100 \%$ de Bioplant ${ }^{\circledR}$, que se constitui em uma mistura de resíduos orgânicos.

Um bom substrato para o desenvolvimento de plântulas deve, ao mesmo tempo, permitir adequadas condições de enraizamento e crescimento de mudas. Assim, o substrato ideal deve apresentar baixa densidade, estabilidade volumétrica e granulométrica, boa porosidade, boa capacidade de retenção de água, aeração e drenagem (ALFENAS et al., 2009).

Os demais tratamentos contendo porcentagens diferentes de Bioplant ${ }^{\circledR}$, Vermiculita ${ }^{\odot}$ e casca de arroz, foram capazes de manter a sobrevivência das mudas próxima a $100 \%$ aos 30 dias avaliados. O único substrato que, aos 90 dias de avaliação permaneceu com uma alta porcentagem de sobrevivência, foi o tratamento S4 $\left(70 \%\right.$ Vermiculita $^{\odot}+30 \%$ casca de arroz).

O tratamento $70 \%$ Vermiculita $^{\odot}+30 \%$ Casca de Arroz apresentou uma maior uniformidade quando comparado aos outros tratamentos (Figura 2), propiciando uma taxa de $95 \%$ de sobrevivência aos 30 dias, mantendo-se uma taxa de $82,5 \%$ aos 90 dias após o início da emergência. Segundo ALFENAS et al. (2009), esta combinação de substratos (Vermiculita ${ }^{\Theta}$ + casca de arroz) adequadamente suplementada com macro e micronutrientes, mesmo apresentando capacidade de troca de cátions relativamente baixa, é um dos substratos mais indicados para germinação (emergência) e desenvolvimento de plântulas de várias espécies, pois apresenta boa drenagem. Além de ser isento de inóculos fitopatogênicos, é de fácil preparo e apresenta custo relativamente baixo.

Ao se tratar da análise descritiva do desenvolvimento em altura nos 30,45 , 60,75 e 90 dias após as plântulas emergidas, o substrato que proporcionou as melhores condições para o crescimento das mudas de $D$. miscolobium foi o tratamento $70 \%$ Vermiculita $^{\odot}+30 \%$ casca de arroz. Este tratamento propiciou um crescimento linear, alcançando até $9,05 \mathrm{~cm}$ de altura aos 90 dias, seguido do tratamento $30 \%$ Bioplant $^{\Theta}+70 \%$ terra de subsolo com $7,57 \mathrm{~cm}$, tratamento $30 \%$ de Bioplant $^{\circledR}+70 \%$ de Vermiculita ${ }^{\odot}$ com $6,44 \mathrm{~cm}$ e por último, o tratamento $S 1(100 \%$ Bioplant $^{\circledR}$ ) com $4,22 \mathrm{~cm}$, aos 90 dias após emergidas (Figura 3).

Nota-se que mesmo as plântulas de $D$. miscolobium tenham se desenvolvido melhor em altura no substrato contendo $30 \%$ de Bioplant $^{\circledR}$ e $70 \%$ de terra de subsolo, este foi o tratamento que proporcionou a maior taxa de mortalidade, como ilustra o Figura 2.

Pode-se verificar que as plântulas presentes no substrato contendo Vermiculita $^{\odot}$ acompanhado de casca de arroz carbonizada, além de se destacar na eficácia de desenvolvimento em altura, apresentaram os índices mais altos de sobrevivência. O mesmo resultado foi encontrado por ANDRADE et al., (2006) ao avaliar o substrato na germinação e desenvolvimento inicial na Dalbergia nigra, concluindo que o substrato com Vermiculita ${ }^{\odot}$ é o mais adequado para a emergência e qualidade das mudas. 


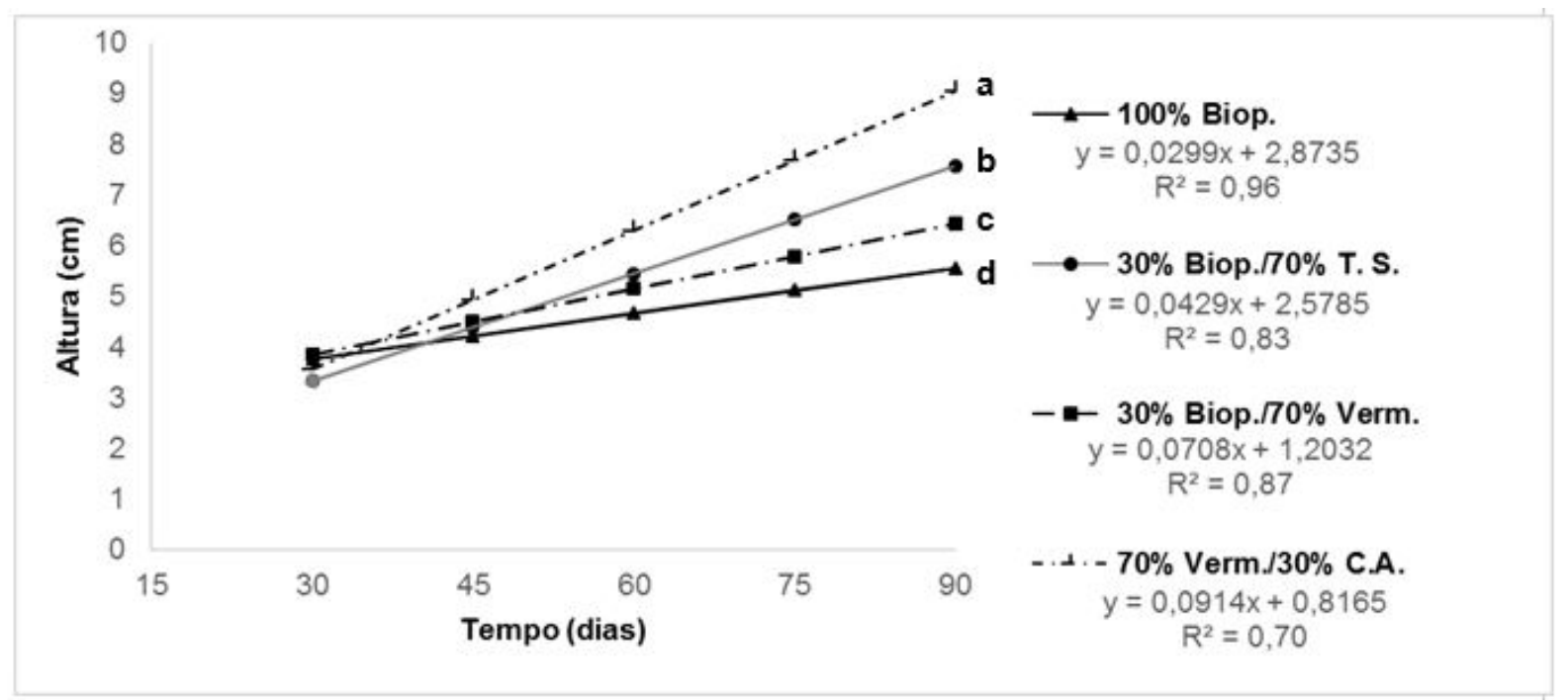

FIGURA 3 - Crescimento em altura $(\mathrm{cm})$ de Dalbergia miscolobium Benth em diferentes substratos avaliados em casa de vegetação nos 30, 45, 60 e 75 dias após a germinação, no CIPEF, Diamantina, MG. Em que: Biop: Bioplant ${ }^{\circledR}$, T.S.: Terra de Subsolo, Verm: Vermiculita ${ }^{\odot}$ e C.A.: Casca de Arroz.

Foi observado no tratamento contendo terra de subsolo (S2) que a maioria das plântulas apresentaram lesões necróticas de cor preta nas folhas, causada pelo ataque do fungo Phoma sp. (FIGURA 4). A infestação pelo fungo provavelmente afetou a sobrevivência e a produtividade de $D$. miscolobium, especialmente por estar dentro da casa de vegetação, um ambiente quente e úmido.

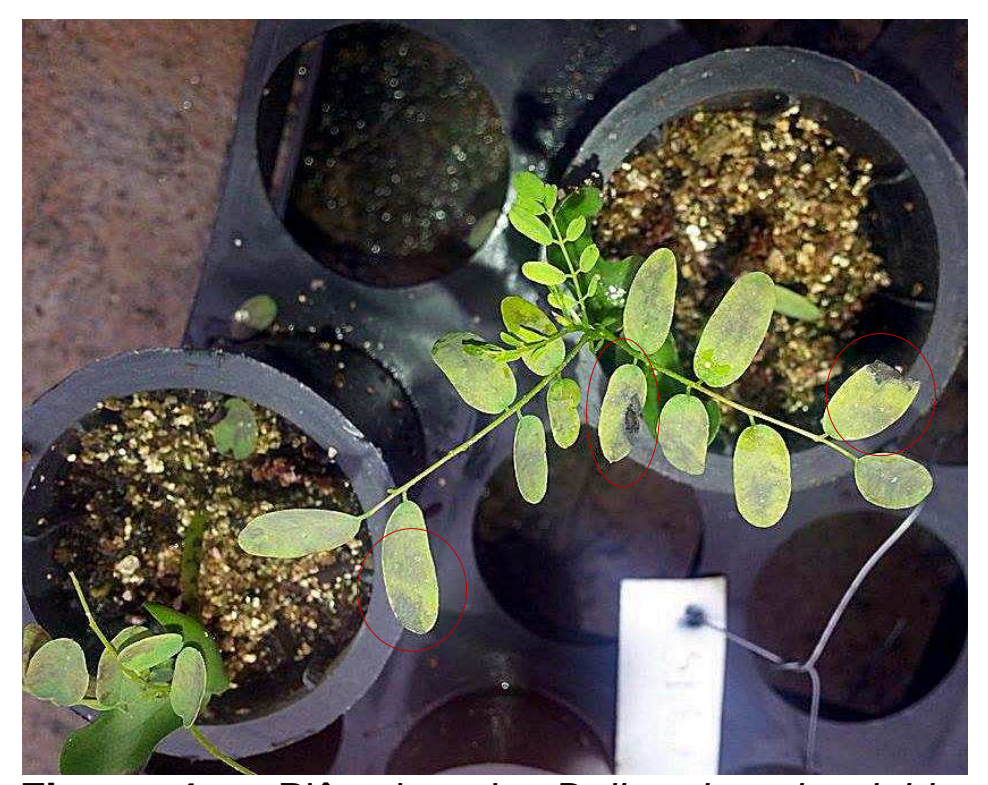

Figura 4 - Plântulas de Dalbergia miscolobium Benth. com lesões necróticas de cor preta nas folhas, causada pelo ataque do fungo Phoma sp, em tratamentos avaliando a eficácia de diferentes substratos, em casa de vegetação, no CIPEF, Diamantina, MG.. 
Apesar de não se ter quantificado os efeitos do patógeno, algumas mudas morreram após serem fortemente infestadas pelo fungo, o que pode ter levado à alta mortalidade no tratamento Terra de subsolo + Bioplant ${ }^{\circledR}$. SILVA JÚNIOR (2012) descreve as características morfológicas e ecológicas da $D$. miscolobium indicando a existência de Phoma nas plântulas de maneira frequente. É observada a presença constante deste fungo de modo geral, em mudas submetidas ao estabelecimento e crescimento no campo sujo (estrato herbáceo contínuo com árvores e arbustos esparsos) e no cerrado sensu stricto, onde a vegetação arbustiva arbórea é mais densa (BRAZL et al., 2000).

O Phoma sp. é um fungo oportunista, e a não esterilização da terra de subsolo, acarretando a ineficiência do controle de agentes fitopatogênicos, pode ter influenciado na infestação nas plântulas do tratamento com Terra de Subsolo (OLIVEIRA FILHO, 2010).

\section{CONCLUSÃO}

O substrato Vermiculita ${ }^{\odot}(70 \%)+$ Casca de Arroz (30\%) é adequado para a produção de mudas de Jacarandá do Cerrado.

Este substrato apresenta boa drenagem, isenção de inóculos fitopatogênicos, fácil preparo e custo baixo.

\section{REFERÊNCIAS}

ALFENAS, A. C.; ZAUZA, E. A. V.; MAFIA, R. G.; ASSIS, T. F. Clonagem e doenças do eucalipto. Viçosa, MG, Ed. UFV. 500p. 2009.

ALMEIDA, S. P. Cerrado: espécies vegetais úteis. Planaltina: Embrapa-CPAC, 464p. 1998.

ANDRADE, A. C. S. PEREIRA, T. S., FERNANDES, M. J., CRUZ, A. P. M., CARVALHO, A. S. R. Substrato, temperatura de germinação e desenvolvimento pósseminal de sementes de Dalbergia nigra. Pesquisa Agropecuária Brasileira, v.41, n.3,

Disponível em: <http://www.scielo.br/scielo.php?script=sci_arttext\&pid=S0100-

204X2006000300020>. doi: 10.1590/S0100-204X2006000300020.

APG III - Angiosperm Phylogeny Group. An update of the Angiosperm Phylogeny Group classification for the orders and families of flowering plants: APG III. Botanical Journal of the Linnean Sociey v.161, p.105-121. 2009. Disponível em: <http://onlinelibrary.wiley.com/doi/10.1111/j.1095-8339.2009.00996.x/abstract $\geq$. doi: 10.1111/j.1095-8339.2009.00996.x.

BOUCHARTDET, D. A.; RIBEIRO, I. M.; SOUZA, N. A.; AIRES, S. S.; MIRANDA, H. S. Efeito de altas temperaturas na germinação de sementes de Plathymenia reticulata Benth. e Dalbergia miscolobium Benth. Revista Árvore, v.39, n.4, p.697705, 2015. Disponível em: <http://www.scielo.br/pdf/rarv/v39n4/0100-6762-rarv-3904-0697.pdf>. doi: 10.1590/0100-67622015000400012.

BRAZL, V. S.; KANEGAEL, M. F.; FRANCOL, A. C. Estabelecimento e desenvolvimento de Dalbergia miscolobium Benth. em duas fitofisionomias típicas dos cerrados do Brasil Central. Acta Botanica Brasilica v.14, p.27-35. 2000. 
Disponível em: <http://dx.doi.org/10.1590/S0102-33062000000100004 _.. doi: $10.1590 /$ S0102-33062000000100004

BRASIL- Ministério do Meio Ambiente- MMA. O bioma Cerrado. 2016. Disponível em: http://www.mma.gov.br/biomas/cerrado.

COSTA, E.; LEAL, P. A. M.; REGO, N. H.; BENATTI, J. Desenvolvimento inicial de mudas de jatobazeiro do cerrado em Aquidauana-MS. Revista Brasileira de Fruticultura, v. $33, \quad$ n.1, p. 215-226, 2011. Disponível em: $<$ http://www.scielo.br/scielo.php?pid=S0100-29452011000100027\&script=sci_abstra ct\&tlng=pt $\leq$. doi: $10.1590 /$ S0100-29452011005000035.

CUNHA, A. O.; ANDRADE, L. A.; BRUNO, R. L. A.; SILVA, J. A. L.; SOUZA, V. C. Efeitos de substratos e das dimensões dos recipientes na qualidade das mudas de Tabebuia impetiginosa (Mart. Ex D.C.) Standl. Revista Árvore, v.29, n.4, p.507-516,2005.

Disponível em: <http://www.scielo.br/scielo.php?script=sci_arttext\&pid=S0100-67622 005000400002 . doi: 10.1590/S0100-67622005000400002

FERNANDES, P. A.; PESSÔA, V. L. S. O cerrado e suas atividades impactantes: uma leitura sobre o garimpo, a mineração e a agricultura mecanizada. OBSERVATORIUM: Revista Eletrônica de Geografia, v.3, n.7, p. 19-37, 2011.

GOMES, J. M.; PAIVA, H, N. Viveiros florestais - propagação sexuada. Viçosa: UFV, 116p. 2011.

GOMES, J. M.; COUTO, L.; BORGES, R. C. G.; FONSECA, E. P. Efeitos de diferentes substratos na produção de mudas de Eucalyptus grandis W.Hill ex Maiden, em “Win-Strip”. Revista Árvore, v. 15, n. 1, p. 35-41, 1991.

GOMES, V.; FERNADES, G. W. Germinação de aquênios de Baccharis dracunculifolia D.C.(Asteraceae). Acta Botanica Brasilica v.16, n.4 , p. 421-427, 2002. Disponível em: <http://www.scielo.br/scielo.php?script=sci_arttext\&pid=S010233062002000400005>. doi: 10.1590/S0102-33062002000400005

GONÇALVES, F. G., ALEXANDRE, R. S., SILVA, A. G., LEMES, E. Q., ROCHA, A. P., RIBEIRO, M. P. A. Emergência e qualidade de mudas de Enterolobium contortisiliquum (Vell.) Morong (Fabaceae) em diferentes substratos. Revista Árvore, v.37, $\quad$ n.6, p.1125-1133, 2013. Disponível em: <http://www.scielo.br/scielo.php?script=sci_arttext\&pid=S010067622013000600014>. doi: 10.1590/S0100-67622013000600014

IBGE - Instituto Brasileiro de Geografia e Estatística. http://www.ibge.gov.br. Acesso em: Março de 2016.

IBGE. Instituto Brasileiro de Geografia e Estatística. Manual Técnico da Vegetação Brasileira. Rio de Janeiro, 271 pg., 2012. ISBN 978-85-240-4272-0.

LORENZI, H. Árvores brasileiras: manual de identificação e cultivo de plantas ENCICLOPÉDIA BIOSFERA, Centro Científico Conhecer - Goiânia, v.13 n.23; p. 568 2016 
arbóreas nativas do Brasil. 1992.

MEIRA JÚNIOR, M. S., MACHADO, E. L. M., OLIVEIRA, M. L. R., PINTO, J. R. R., MOTA, S. L. L. Qualidade das sementes de indivíduos nativos de Dalbergia miscolobium Benth. (FABACEAE) em área de Cerrado em processo de recuperação. Heringeriana. v.7, p.73-78. 2013.

NAKAGAWA, J. Testes de vigor baseados no desempenho das plântulas In: KRZYZANOWSKI, F.C.; VIEIRA, R.D.; FRANÇA NETO, J.B. Vigor de sementes: conceitos e testes. Londrina: Abrates, p. 2.1-2.24, 1999.

NOGUEIRA, F. C. B.; GALLÃO, M. I.; BEZERRA, A. M. E.; MEDEIROS FILHO, S. Efeito da temperatura e luz na germinação de sementes de Dalbergia cearenses Ducke. Ciência Florestal, v.24, n.4, p.997-1007, 2014. Disponível em: $<$ http://www.scielo.br/scielo.php?script=sci arttext\&pid=S198050982014000400997>. Doi: 10.1590/1980-509820142404019.

OLIVEIRA FILHO, J. Estudos em Doenças de Plantas: Aspectos Gerais e Morfológicos do Fungo Phoma sp. In: http://www.fitopatologia1.blogspot.com. 2010.

PAIVA, H.N.; GOMES, J.M. Propagação vegetativa de espécies florestais. Viçosa: Imprensa Universitária UFV,1993.

REIS, B. E.; PAIVA, H. N.; BARROS, T. C.; FERREIRA, A. F.; CARDOSO, W. C. Crescimento e qualidade de mudas de Jacarandá-da-Bahia (Dalbergia nigra (Vell.) Allemão ex Benth.) em resposta à adubação com potássio e enxofre. Ciência Florestal, v.22, n.2, p.389-396, 2012. Disponível em: < http://dx.doi.org/10.5902/198050985746>. doi: 10.5902/198050985746

SASSAKI, R. M. Desenvolvimento inicial de Dalbergia miscolobium. 1991. $178 \mathrm{f}$. Dissertação (Mestrado em Biologia) - Instituto de Biologia, Universidade Estadual de Campinas,1991.

SILVA JÚNIOR, M. C. 100 árvores do Cerrado- sentido restrito: guia de campo. Brasília. 304p. 2012.

SILVA, A. L. \& MORAIS, G. A. Influência de diferentes substratos no crescimento inicial de Ormosia storage (Vell.) Harms (Fabaceae). Revista Verde (Mossoró RN), v. 8, n. 4, p. 22-27, 2013.

SILVA, E. A.; OLIVEIRA, A. C.; MENDONÇA, V.; SOARES, F. M. Substratos na produção de mudas de Mangabeira em tubetes. Pesquisa Agropecuária Tropical. v.41, n.2, p.279-285, 2011.

SILVA, T. R. G.; CORTELAZZO, A. L.; DIETRICH, S. M. C. Variations in storage compounds during germination and early plantlet growth of Dalbergia miscolobium. Revista Brasileira de Fisiologia Vegetal, v.10, p.119-124, 1998.

TOKARNIA, M. Berço das águas, Cerrado precisa de proteção para garantir abastecimento no país. Agência Brasil. EBC. 2015. Disponível em: 
agenciabrasil.ebc.com.br/.

TOLEDO, A. R. M. Efeito de substratos na formação de mudas de laranjeira (Citrus sinensis (L.) OSBECK cv. "Pêra Rio") em vaso. 1992. 88 f. Dissertação (Mestrado em Fitotecnia) - Escola Superior de Agricultura de Lavras, Lavras, 1992. 